\section{Shcherban V., Zhdanyuk N., Plemyannikov $\mathbf{M}$.}

\title{
STUDY OF THE DYNAMICS OF STRESS FORMATION IN GLASS DURING A THERMAL HARDENING
}

The object of research is the ultimate bending strength of float glass sheet $4 \mathrm{~mm}$ thick. The paper confirms that the main factor affecting the increase in glass strength is the dynamics of stress formation in the surface and inner layers of glass. Rapid cooling of float glass with an air flow for $8-10 \mathrm{~s}$ at a rate of $25^{\circ} \mathrm{C} / \mathrm{s}$ leads to the appearance in the glass of an average temperature difference in the surface zone of $30^{\circ} \mathrm{C} / \mathrm{mm}$. It was found that during thermal hardening at temperatures exceeding the glass transition temperature limit, there is an abrupt increase in the glass bending strength. A comparative analysis of the results of measuring the bending strength of glass for float glass and heat-strengthened glass indicates that this indicator is significantly improved. The statistical analysis of the results shows that the scatter of the values of the bending strength of annealed glass falls within the range of 30-50 MPa, and the most probable value is $40 \mathrm{MPa}$. At the same time, the spread in the values of the bending strength of thermally hardened glass is in the range of 100-160 MPa and is $135 \mathrm{MPa}$. The work proved that thermal hardening of float glass sheets increases its flexural strength by about 3.5 times. The peculiarities of the change in the type of the hardening stress diagram over time have also been studied: thermal hardening causes a more gentle course of the residual stress curve compared to hardening. In this case, the coordinate of the critical tensile stress $\sigma_{\text {crit }}$ can be located on the lower surface of the glass, which will make it possible to fracture at lower loads compared to quenching, but the fracture mechanism will be identical as for annealed glass. In this case, the destruction mechanism will be approximately the same as in the case of annealed glass, but its actual strength will be 2-3 times higher.

Keywords: sheet float glass, thermal hardening, stress diagram, bending strength.

Received date: 06.08 .2020

Accepted date: 24.09 .2020

Published date: 31.12 .2020
Copyright (C) 2020, Shcherban V., Zhdanyuk N., Plemyannikov M. This is an open access article under the CC BY license (http://creativecommons.org/licenses/by/4.0)

\section{Introduction}

The flexural strength of ordinary glasses does not exceed $1 \%$ of the theoretically calculated glass strength. Low glass strength is explained by the presence of defects on its surface: microcracks, scratches, dents and other damages, which are stress concentrators and give rise to rupture when a certain load is added to the glass [1]. Increasing the strength of glass can be carried out by tempering, ion exchange, deposition on the surface of a glass layer with a lower coefficient of expansion than the main glass, crystallization of the surface layer, etc. [2, 3].

Based on the nature of glass as a material with surface defects, glass strengthening methods can be divided into thermal, chemical, and thermochemical.

The thermal method of increasing the strength of glass consists in heating above the forcing temperature $\left(T_{g}\right)$ and very fast cooling (hardening) or rather slowly (heat hardening) in an air stream. As a result of such processes, compressive stresses are formed on the glass surface. As it is possible to see, the physics of both processes is similar. During quenching, the thermal effect is more radical, while during thermal hardening it is softer. These processes are carried out by rapid cooling in jets of air or in organic or other liquids, metal melts and other media. The most widespread method of hardening is air hardening, as a result of which residual stresses appear in the glass: the outer layers of the glass are compressed, and the inner layers are stretched [4]. Glass hardening increases the mechanical strength by about 5 times compared to ordinary glass, and heat strengthening - by about 2-3 times [5, 6]. To achieve these results, the compression on the glass surface must extend to a depth greater than the depth of the defects. Dangerous defects on the surface are usually formed at a depth of up to 100 microns, less often up to 200-300 microns.

The second way of strengthening is chemical surface treatment. In this case, surface defects are removed by etching glass, most often with solutions of hydrofluoric acid or its mixture with sulfuric, nitric or phosphoric acids. During digestion, about 50-150 microns of the glass surface is removed, which makes it possible to increase its bending strength by 4.5 times. This method of strengthening glass is somewhat more expensive, but it allows high compressive stresses to be obtained and allows the processing of glass of thinner thickness. Another method of chemical strengthening of glass is associated with the deposition of thin films of polyorganosiloxanes or silicic acid polymers on its surface, which reduce the wedging effect of moisture in glass microcracks $[7,8]$.

The thermochemical method of glass strengthening consists in changing the structure and properties of the glass surface layer. Thus, the strength of glass subjected to digestion and then tempering increases in comparison with the strength of tempered glass [9].

The thermal method of strengthening glass is the oldest way to increase its strength. This method allows the 
strengthening of large-format glass sheets. It is also worth noting that this method is less energy consuming compared to hardening and more environmentally friendly compared to chemical strengthening methods. Thermally strengthened glass breaks into larger fragments than tempered glass, but in both cases without sharp corners, which prevents the possibility of serious injury. However, thermally strengthened glass has better surface compression uniformity and is characterized by less optical distortion of the image (this is especially important when glass is used in facades with a high degree of reflection). Thus, the study of the processes of thermal strengthening of glass and the study of bending strength is an urgent task.

Thus, the object of research is the ultimate bending strength of float glass sheet with a thickness of $4 \mathrm{~mm}$. And the aim of research is to determine the influence of the distribution of the temperature field that occurs in the glass plate during heat hardening and its effect on the value of the flexural strength.

\section{Methods of research}

Let's used float glass $4 \mathrm{~mm}$ thick manufactured by SaintGobain. Float glass is characterized by the presence of stresses of $30 \mathrm{~nm} / \mathrm{cm}$ uniformly distributed over the entire surface. The chemical composition of the samples is given in Table 1.

Table 1

Chemical composition of glass samples, mass \%

\begin{tabular}{|c|c|c|c|c|c|c|}
\hline $\mathrm{SiO}_{2}$ & $\mathrm{Na}_{2} \mathrm{O}$ & $\mathrm{CaO}$ & $\mathrm{MgO}$ & $\mathrm{Al}_{2} \mathrm{O}_{3}$ & $\mathrm{SO}_{3}$ & $\mathrm{Fe}_{2} \mathrm{O}_{3}$ \\
\hline 71.8 & 14.1 & 8.8 & 4.2 & 0.7 & 0.3 & 0.1 \\
\hline
\end{tabular}

For studies of thermal hardening, glass specimens with a size of 70-20-4 mm were cut. The obtained samples were enclosed in a cassette of nichrome wire on the edge and heated in a muffle furnace to a temperature of about $600{ }^{\circ} \mathrm{C}$. After heating, the cassette with plates was removed from the furnace and immediately subjected to intensive blowing with a fan. To determine the evolution of the temperature field in the plate, exposed junctions of chromel-alumel thermocouples were fused to different depths. The coordinates of local point measurements of temperatures are as follows: the middle of the plate $(h=0 \mathrm{~mm})$, one fourth of the plate thickness $-(h=1 \mathrm{~mm})$, the surface $-(h=2 \mathrm{~mm})$. The temperature values of the inner and surface layers of glass were recorded using a digital camera. Rapid cooling of the samples occurred at a rate of $25{ }^{\circ} \mathrm{C} / \mathrm{s}$. The heat hardening process took place within $8-10 \mathrm{~s}$.

Flexural strength was calculated using the formula:

$$
\sigma_{f l}=\frac{3 \cdot F \cdot L}{2 \cdot b \cdot \delta^{2}}, \quad \mathrm{~Pa}(\mathrm{MPa}),
$$

where $F$ - breaking load, N; $L$ - distance between supports, m; $b$ - sample width, $\mathrm{m} ; \delta$ - sample thickness, $\mathrm{m}$.

Strength test results for glass give poor reproducibility due to unpredictable surface defects. When determining the strength of glass samples, a significant scatter of strength values is observed, exceeding the measurement accuracy. The statistical theory of strength makes it possible to calculate the most probable value of the strength of a glass sample, close in magnitude to the average values of its technical strength. And also to determine the spread of experimentally found strength values, which characterizes the heterogeneity of the tested material samples.

The probability distribution of a continuous random variable is described by the Gaussian function:

$$
\varphi(x)=\frac{1}{\sigma \sqrt{2 \pi}} \cdot e^{-\frac{(x-m)^{2}}{2 \sigma^{2}}} .
$$

The formula consists of two mathematical constants: $\pi-$ pi $-3.142 ; e$ - base of natural logarithm - 2.718; two variable parameters that specify the shape of a specific curve: $m$ - mathematical expectation (different sources may use other designations, for example, $\mu$ or $a$ ); $\sigma^{2}$ variance; the variable $x$ for which the probability density is calculated.

\section{Research results and discussion}

The physical meaning of glass reinforcement by the method of creating a compressed surface layer can be illustrated as follows: the destruction of a glass product mostly occurs under the influence of static and dynamic loading, concentrated in a certain middle part of a certain glass wall [5].

In bending studies, a plane-parallel glass beam is located on two supports, and a point load $F$ acts on it in the middle part of the opposite side (Fig. 1, $a, b$ ). The diagram of mechanical stresses arising in glass under load is represented by a straight line. The maximum compressive stress is at the top surface and tensile stress is at the bottom. There is no stress on average. Glass works in tension many times worse than in compression. Therefore, failure will occur on the lower stretched surface. When hardening (Fig. 1, $a$ ), or thermal hardening (Fig. 1, $b$ ) of such a beam, the surface zones will retain residual compressive stresses, and the inner zone will retain tension. The occurrence of tensile stresses in the middle zone within acceptable limits will not introduce a risk of sample failure. First, these tensile stresses are significantly lower than the compressive stresses on the surfaces. Secondly, and this is the main thing, there are no surface defects in the inner part of the glass that weaken it on the surface.


$b$

Fig. 1. Stress diagrams: $a$ - tempered glass; $b$ - thermally hardened glass. Stress: - - mechanical; ..... - thermal; -- - total

If a preliminary force $F$ is applied to such a prestressed beam, then stresses will be added. The summary resulting plot is shown in Fig. 1, $a$. Compression stresses are added at the top of the beam cross section. In this case, the maximum of this amount will necessarily be on the upper surface, but there will be no risk of destruction, because the glass is «not afraid» of compression. In the lower part of the beam section, when an increasing force $F$ is applied, the residual compressive stresses begin to be neutralized by the tensile 
stresses created. At some point, the tension on the bottom surface will disappear. With a further increase in the load $F$, the lower part of the beam section will already be completely under the action of tensile stress. In this case, the critical stress $\sigma_{c r i t}$, which corresponds to the maximum tensile stress and which, upon reaching a certain value, can cause the destruction of the product, can be located at some distance from the lower surface, as shown in Fig. 1, $a$. And this will be the desired option, since there are no defects in the inner zone of the sample and the glass works better in tension. This option is achieved with the so-called glass tempering. The destruction of the samples will take place explosively under high loads. Detonation will lead to fragmentation of the product into small fragments [10].

If the glass was heat-strengthened in Fig. 1, $b$, the stress pattern will be slightly different. A «softer» thermal effect (partial hardening) will lead to a flatter course of the residual stress curve. In this case, the coordinate of the critical tensile stress $\sigma_{\text {crit }}$ can be located on the lower surface. The presence of surface defects will lead to destruction at lower loads. And in this case, the mechanism of destruction will be approximately the same as in the case of ordinary glass, with the only difference that the actual strength will be approximately $2-3$ times higher.

Compression stresses on the glass surface depend on the cooling intensity and reach $250 \mathrm{MPa}$ for air-jet cooling, and $500 \mathrm{MPa}$ for cooling in liquids. Internal tensile stresses are less and do not exceed 80-90 MPa.

Air hardening of glass with a small thickness (less than $5 \mathrm{~mm}$ ) and/or a low coefficient of linear thermal expansion is ineffective. In this case, it is rational to carry out hardening in liquid media to increase the heat transfer coefficient. For example, in oils with a high flash point or in organosilicon fluids.

Thermal strengthening of glass was carried out in the laboratory and the parameters of the temperature field were determined. Fig. 2 shows the evolution of the temperature field during thermal hardening, the so-called chronothermogram (evolution of temperatures in time) for the indicated coordinates and top thermogram (evolution of temperatures in space) for certain points in time. The cooling rate of the surface in the temperature range suitable for thermal hardening was about $25^{\circ} \mathrm{C} / \mathrm{s}$. The temperature difference between the center and the surface is averaged $60{ }^{\circ} \mathrm{C}$. It should also be noted that the temperature profile in the samples approached a quadratic parabola, which is typical for the regular regime [11].

The criterion for the effectiveness of thermal strengthening of glass should be the results of experimental measurements of certain mechanical properties. In this work, the flexural strength was investigated. Since, as is known, the results of such studies give poor reproducibility, there is a significant scatter of values. To process the results, the theory of probability was used and the most probable values were determined. As a result of calculations, Gauss curves were constructed [12]. The results are presented in the form of probability diagrams and are presented in Fig. 3.

Thus, the distribution of bending strength values for annealed glass is in the range of $30-50 \mathrm{MPa}$, and the most probable value is $40 \mathrm{MPa}$. At the same time, the spread in the values of the bending strength of thermally hardened glass is in the range of $100-160 \mathrm{MPa}$ and is $135 \mathrm{MPa}$.

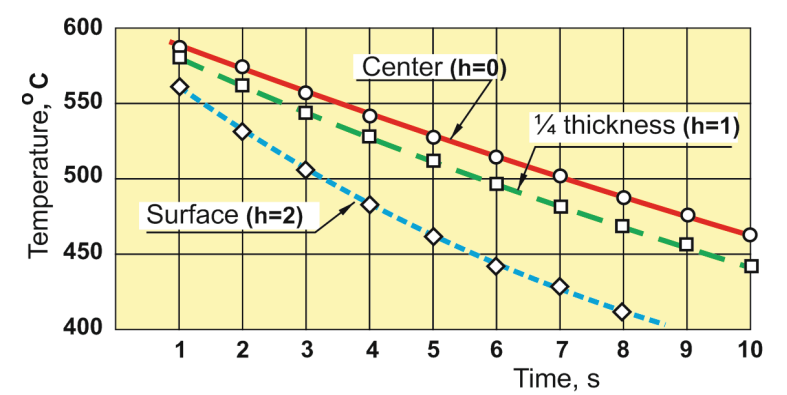

a

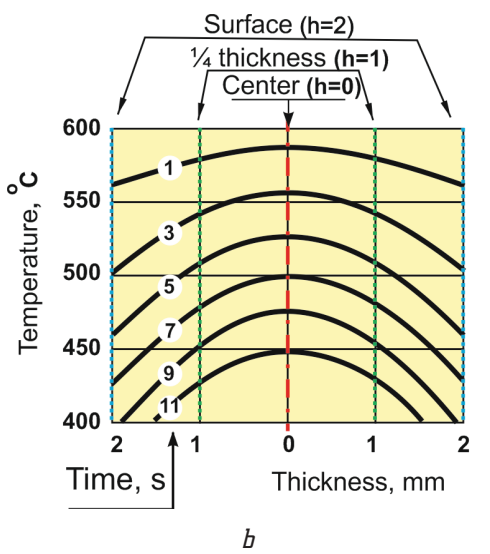

Fig. 2. Evolution of the temperature field: $a$ - evolution of temperatures in time; $b-$ evolution of temperatures in space



a

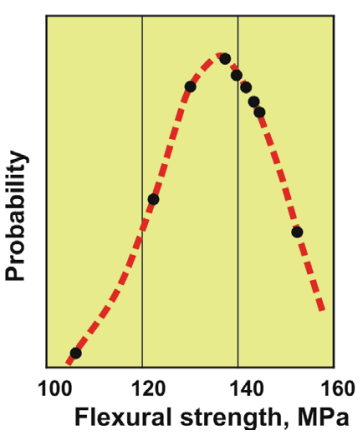

Fig. 3. Comparative statistics of flexural strength values: $a$ - annealed glass; $b$ - thermally hardened glass

\section{Conclusions}

In the course of the study, it has been found that the rapid cooling of float glass with an air flow for $8-10 \mathrm{~s}$ at a rate of $25^{\circ} \mathrm{C} / \mathrm{s}$ leads to the appearance in the glass of an average temperature difference in the surface zone of $30{ }^{\circ} \mathrm{C} / \mathrm{mm}$. It has been established that during thermal hardening at temperatures exceeding the glass transition temperature limit, there is an abrupt increase in the glass bending strength. Analysis of the flexural strength has been shown that for annealed float glass the most probable value is $40 \mathrm{MPa}$, and for thermally hardened glass $135 \mathrm{MPa}$. Thus, it can be stated that thermal hardening of float glass sheet $4 \mathrm{~mm}$ thick increases its flexural strength by about 3.4 times. The research results will be useful in choosing a glass hardening method and establishing its parameters.

\section{References}

1. Pisano, G., Carfagni, G. R. (2017). A micromechanical derivation of the macroscopic strength statistics for pristine or 
corroded/abraded float glass. Journal of the European Ceramic Society, 37 (13), 4197-4206. doi: http://doi.org/10.1016/ j.jeurceramsoc.2017.04.046

2. Koike, A., Akiba, S., Sakagami, T., Hayashi, K., Ito, S. (2012) Difference of cracking behavior due to Vickers indentation between physically and chemically tempered glasses. Journal of Non-Crystalline Solids, 358 (24), 3438-3444. doi: http:// doi.org/10.1016/j.jnoncrysol.2012.02.020

3. Li, X., Jiang, L., Wang, Y., Mohagheghian, I., Dear, J. P., Li, L., Yan, Y. (2017). Correlation between $\mathrm{K}+-\mathrm{Na}+$ diffusion coefficient and flexural strength of chemically tempered aluminosilicate glass. Journal of Non-Crystalline Solids, 471, 72-81. doi: http:// doi.org/10.1016/j.jnoncrysol.2017.05.011

4. Guerette, M., Ackerson, M. R., Thomas, J., Yuan, F., Bruce Watson, E., Walker, D., Huang, L. (2015). Structure and Properties of Silica Glass Densified in Cold Compression and Hot Compression. Scientific Reports, 5 (1). doi: http://doi.org/ 10.1038/srep15343

5. Nyounguè, A., Bouzid, S., Dossou, E., Azari, Z. (2016). Fracture characterisation of float glass under static and dynamic loading. Journal of Asian Ceramic Societies, 4 (4), 371-380. doi: http://doi.org/10.1016/j.jascer.2016.07.004

6. Uaiett, O., Diu-Khiuz, D.; Liubova, B. Iu. (Ed.) (1979). Metally, keramiki, polimery Vvedenie $k$ izucheniiu $i$ struktury $i$ svoistv tekhnicheskikh materialov. Moscow: Atomizdat, 580.

7. Sundberg, P., Grund Bäck, L., Orman, R., Booth, J., Karlsson, S. (2019). Simultaneous chemical vapor deposition and thermal strengthening of glass. Thin Solid Films, 669, 487-493. doi: http:// doi.org/10.1016/j.tsf.2018.11.028

8. Sheth, N., Hahn, S. H., Ngo, D., Howzen, A., Bermejo, R., van Duin, A. C. T. et. al. (2020). Influence of acid leaching surface treatment on indentation cracking of soda lime silicate glass. Journal of Non-Crystalline Solids, 543. doi: http://doi.org/ 10.1016/j.jnoncrysol.2020.120144
9. Wang, Z., Guan, T., Ren, T., Wang, H., Suo, T., Li, Y. et. al. (2020). Effect of normal scratch load and HF etching on the mechanical behavior of annealed and chemically strengthened aluminosilicate glass. Ceramics International, 46 (4), 4813-4823. doi: http://doi.org/10.1016/j.ceramint.2019.10.214

10. Ballarini, R., Pisano, G., Royer Carfagni, G. (2016). New calibration of partial material factors for the structural design of float glass. Comparison of bounded and unbounded statistics for glass strength. Construction and Building Materials, 121, 69-80. doi: http://doi.org/10.1016/j.conbuildmat.2016.05.136

11. Plemiannikov, M. M., Krupa, A. A. (2000). Khimiia ta teplofizyka skla. Kyiv: NTUU «KPI», 560.

12. Chumak, V. L., Ivanov, S. V., Maksymiuk, M. R. (2012). Osnovy naukovykh doslidzhen. Kyiv: NAU-druk, 360.

Shcherban Vladyslav, Department of Chemical Technology of Ceramics and Glass, National Technical University of Ukraine «Igor Sikorsky Kyiv Polytechnic Institute», Kyiv, Ukraine, e-mail: shcherban.vlad1997@gmail.com, ORCID: http://orcid.org/00000002-7233-4267

Zhdanyuk Nataliya, PhD, Assistant, Department of Chemical Technology of Ceramics and Glass, National Technical University of Ukraine «Igor Sikorsky Kyiv Polytechnic Institute», Kyiv, Ukraine, e-mail: zhdanyukn.kpi@gmail.com, ORCID: http://orcid.org/00000003-3771-5045

Plemyannikov Mykola, PhD, Associate Professor, Department of Chemical Technology of Ceramics and Glass, National Technical University of Ukraine «Igor Sikorsky Kyiv Polytechnic Institute», Kyiv,Ukraine,e-mail:plemja46@gmail.com,ORCID:http://orcid.org/ 0000-0003-4756-3540 